\title{
PERBAIKAN STASIUN KERJA PACKING DAN CARDING FIBER DACRON (POLIETILENA TEREFTALAT) UNTUK MENCEGAH MUSCULOSKELETAL DISORDER (MSDs) PADA PEKERJA PT. XYZ CIKUPA TANGERANG
}

\author{
Lamto Widodo, Adianto dan Felicia \\ Program Studi Teknik Industri Universitas Tarumanagara \\ e-mail: lamtow@ft.untar.ac.id
}

\begin{abstract}
ABSTRAK
PT. XYZ bertempatkan di Cikupa Tangerang dan bergerak dalam bidang produksi polietilena tereftalat atau lebih dikenal dengan nama fiber dacron. Penelitian difokuskan kepada stasiun kerja carding dan packing dimana proses kerja yang dilakukan masih secara manual. Pekerja banyak melakukan gerakan membungkuk secara repetitif untuk pengambilan dacron yang menyebabkan tingginya keluhan pada bagian punggung, leher atas, pinggang, bawah pinggang dan lengan bawah kanan. Langkah perbaikan dilakukan dengan mendesain alat bantu kerja carding dan packing berupa garpu dacron dan meja packing. Setelah diimplementasikan, didapatkan penurunan skor REBA yang awalnya untuk proses carding memiliki skor maksimal 12, skor turun menjadi 6 sedangkan untuk proses packing,skor maksimal yang awalnya sebesar 11, turun menjadi 4. Sehingga menurut hasil skor REBA,tingkat resiko MSDs yang awalnya sangat tinggi menjadi medium. Selain itu juga dilakukan analisis OWAS yang menghasilkan penurunan kategori kerja satu tingkat sehingga pekerjaan yang awalnya jelas berbahaya turun menjadi sedikit berbahaya. Dan terakhir dilakukan analisis IRHR yang menyatakan pekerjaan carding dan packing yang awalnya termasuk pekerjaan berat, setelah dilakukan implementasi perbaikan menjadi pekerjaan sedang.
\end{abstract}

Kata Kunci: Nordic Body Map, REBA, OWAS, IRHR, AHP

\begin{abstract}
PT. XYZ is located in Cikupa Tangerang and specialized in polietilena terfertalat's production or known as fiber dacron. This study will be focusing on the carding and packing work station which is still manually done. The workers mostly do repetitive movements for picking up dacron from the floor which is causing pain for workers in the back area, upper neck, waist, lower waist, and lower arms. Corrective measures are designed in the form of shovel fork for dacron and packing table for helping carding and packing processes. The REBA score was decreasing quite significantly after the corrective measures were implemented. For carding process, the REBA score is 6, decreasing from the number of 12 previously.And for packing process, the REBA Score is 4, decreasing from 11 previously. In conclusion, the risk of MSD becomes medium for both processes. Furthermore, the result of OWAS analysis indicates the hazard of both processes has been decreased from $3^{\text {rd }}$ category to the $2^{\text {nd }}$ category which means it has a little possibility of danger. And the last, IRHR analysis indicates after the corrective measure implementation, both processes has been categorized into medium works.
\end{abstract}

Keywords: Nordic Body Map, REBA, OWAS, IRHR, AHP

\section{PENDAHULUAN}

Perancangan sistem kerja adalah suatu ilmu yang terdiri dari teknik-teknik dan prinsipprinsip untuk mendapatkan rancangan terbaik dari sistem kerja yang bersangkutan [1]. Ruang lingkup perancangan sistem kerja terbagi atas dua bagian yaitu yang pertama bersifat menata unsur-unsur sistem kerja dan kedua yaitu yang bersifat mengukur kebaikan rancangan sistem.

Masalah yang timbul pada pekerja akibat stasiun kerja yang tidak ergonomis banyak dialami oleh industri-industri kecil hingga industri besar. Salah satunya terjadi pada PT.
XYZ yang bergerak di bidang industri dacron (polietilena tereftalat) yang terletak di Cikupa, Tangerang. Dalam produksi dacron ini seluruh sistem telah menggunakan otomasi mesin kecuali pada stasiun kerja carding dan packing yang melibatkan banyak gerakan repetitif dalam posisi yang kurang nyaman bagi pekerja.

Dalam stasiun kerja carding dan packing, dacron yang selesai diproduksi akan dikirim dari stasiun kerja sebelumnya. Sistem kerja pada stasiun ini diawali dari proses carding dacron, packing memasukkan dacron ke dalam karung, kemudian penyimpanan dacron. 
Dacron disimpan dalam bentuk bal akan di buka di lantai untuk melalui proses carding. Selama proses carding berlangsung, pekerja akan mengambil uraian dacron di lantai kerja sedikit demi sedikit untuk dimasukkan ke dalam mesin carding hingga habis. Dacron yang telah melalui proses carding akan di packing dalam karung dengan cara pekerja membungkuk mengambil dacron dari lantai kerja untuk dimasukkan ke dalam karung sedikit demi sedikit hingga habis.

Perbaikan stasiun kerja difokuskan terhadap pencegahan musculoskeletal disorder (MSDs) pada karyawan PT. XYZ berdasarkan pengamatan dan wawancara, mempertimbangkan cukup banyaknya pekerja yang melakukan gerakan repetitif, posisi tubuh pekerja yang kurang nyaman, cepat lelahnya pekerja dalam melaksanakan pekerjaan, banyaknya gerakan membungkuk, memutar, serta gerakan lainnya yang dapat memicu cedera apabila dilakukan secara terus-menerus.

\section{Antropometri}

Antropometri merupakan ilmu yang secara khusus mempelajari tentang pengukuran tubuh manusia guna merumuskan perbedaan ukuran tiap individu maupun kelompok [2]. Menurut Sutalaksana (2006), data-data antropometri digunakan dalam tiga prinsip yaitu perancangan berdasarkan individu yang ekstrim, perancangan fasilitas yang bisa disesuaikan, dan perancangan individual.
Prinsip-prinsip tersebut digunakan dalam menentukan ukuran rancangan yang akan dibuat. Data bagian-bagian tubuh manusia yang diukur dimensinya dapat dilihat pada Gambar 1.

\section{Nordic Body Map}

Nordic Body Map merupakan kuesioner keluhan fisik yang digunakan berdasarkan 27 postur tubuh yang dikembangkan dari Nordic Musculoskeletal Questionnaire (NMQ) [4]. Dalam penelitian ini akan digunakan Nordic Body Map dengan tingkat keluhan A, B, C dan D. Keterangan dari masing-masing tingkat keluhan tersebut dapat dilihat pada Tabel 1.

\section{Rapid Entire Body Assessment}

Metode REBA dikembangkan oleh Dr. Sue Hignett dan Dr. Lynn McAtamney dalam jurnal original berjudul Rapid Entire Body Assessment (REBA) pada tahun 2000 [5]. Enam langkah melakukan analisis REBA [6] adalah mengobservasi pekerjaan, memilih postur untuk diukur, memberi skor pada postur, memproses skor, menyusun skor REBA, menyesuaikan level resiko dengan tindakan perbaikan.

Tabel 1. Keterangan Keluhan NBM

\begin{tabular}{cc}
\hline Tingkat Keluhan & Keterangan \\
\hline A & Tidak sakit/nyeri \\
B & Agak sakit/nyeri \\
C & Sakit/nyeri \\
D & Sangat sakit/nyeri \\
\hline
\end{tabular}

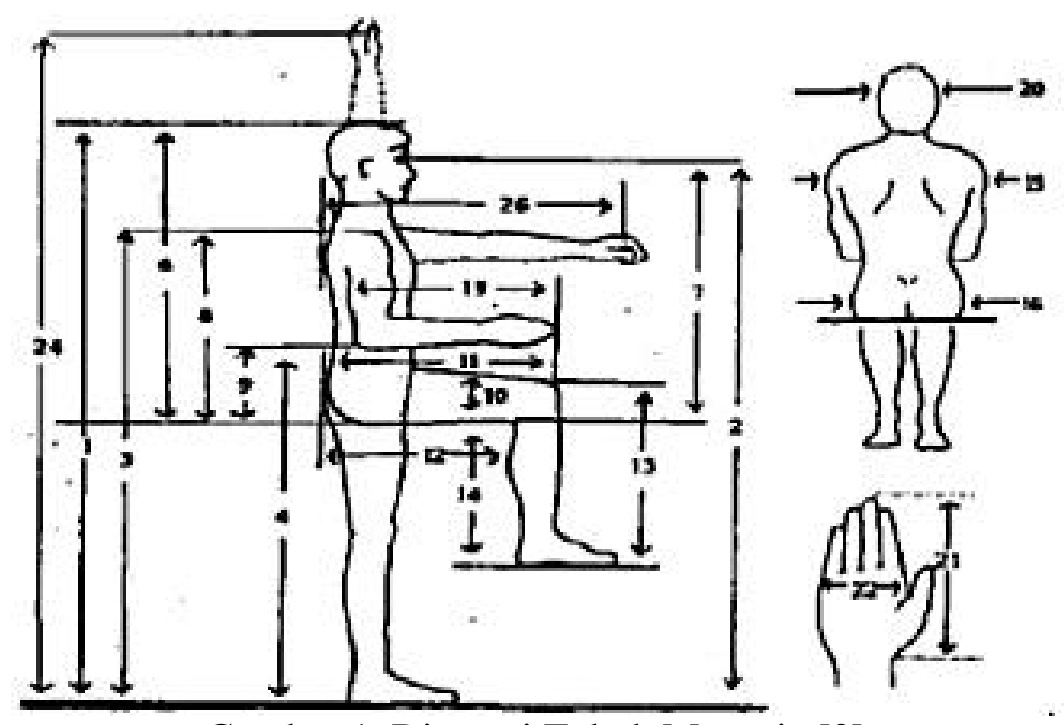

Gambar 1. Dimensi Tubuh Manusia [3] 
Evaluasi menggunakan REBA Worksheet, dilakukan dengan memberikan skor pada bagian tubuh tertentu yaitu pergelangan tangan, lengan bagian bawah, siku, bahu, leher, bagian depan tubuh, punggung, kaki dan lutut. Setelah semua data didapatkan, akan ditemukan variabel faktor resiko yang mempresentasikan level resiko pada MSD. Level resiko dapat dilihat pada Tabel 2.

Tabel 2. Level Resiko REBA

\begin{tabular}{|c|l|}
\hline Score & Level of MSD Risk \\
\hline 1 & negligible risk, no action required \\
\hline $2-3$ & low risk, change may be needed \\
\hline $4-7$ & medium risk, further investigation, change soon \\
\hline $8-10$ & high risk, investigate and implement change \\
\hline $11+$ & very high risk, implement change \\
\hline
\end{tabular}

\section{Ovako Work Posture Analysis System}

Metode Ovako Work Posture Analysis System (OWAS) merupakan suatu metode untuk mengevaluasi dan menganalisis sikap kerja operator yang diaamati meliputi gerakan tubuh bagian punggung, bahu, tangan dan kaki termasuk paha lutut dan pergelangan kaki [7]. Metode OWAS dikembangkan di Finland pada tahun 1973 oleh perusahaan baja Ovako Oy. Cara penulisan kode identifikasi OWAS pada postur yang telah ditentukan dapat dilihat pada Gambar 2. didapatkan, maka hasil skor dapat disesuaikan pada tabel penilaian standar OWAS untuk menentukan kategori postur kerja. Hasil kategori dinyatakan berdasarkan angka 1 hingga 4 yang masing-masing memiliki keterangan yang dapat dilihat pada Tabel 3.

Tabel 3. Kategori OWAS [9]

\begin{tabular}{|c|c|}
\hline Kategori & Keterangan \\
\hline 1 & $\begin{array}{l}\text { Postur normal, tidak memerlukan } \\
\text { perbaikan }\end{array}$ \\
\hline 2 & $\begin{array}{l}\text { Sedikit berbahaya, perlu perbaikan di } \\
\text { masa mendatang }\end{array}$ \\
\hline 3 & $\begin{array}{l}\text { Jelas berbahaya, perbaikan perlu } \\
\text { dilakukan secepat mungkin }\end{array}$ \\
\hline 4 & $\begin{array}{l}\text { Sangat berbahaya, perbaikan perlu } \\
\text { dilakukan sekarang juga }\end{array}$ \\
\hline
\end{tabular}

\section{Increase Ratio of Heart Rate}

Konsumsi dan pengeluaran energi digunakan pada saat melakukan kerja fisik. Konsumsi energi dapat diukur secara tidak langsung salah satunya adalah dengan melakukan pengukuran denyut jantung.

Perbandingan antara denyut jantung pada saat kerja (HR work) dengan denyut jantung pada saat istirahat (HR rest) menghasilkan nilai perbandingan yang dikenal dengan nama increase ratio of heart rate (IRHR) [10]. Perbandingan tersebut dirumuskan sebagai berikut.

IRHR $=$ HR work $/$ HR rest

Berdasarkan kode identifikasi yang

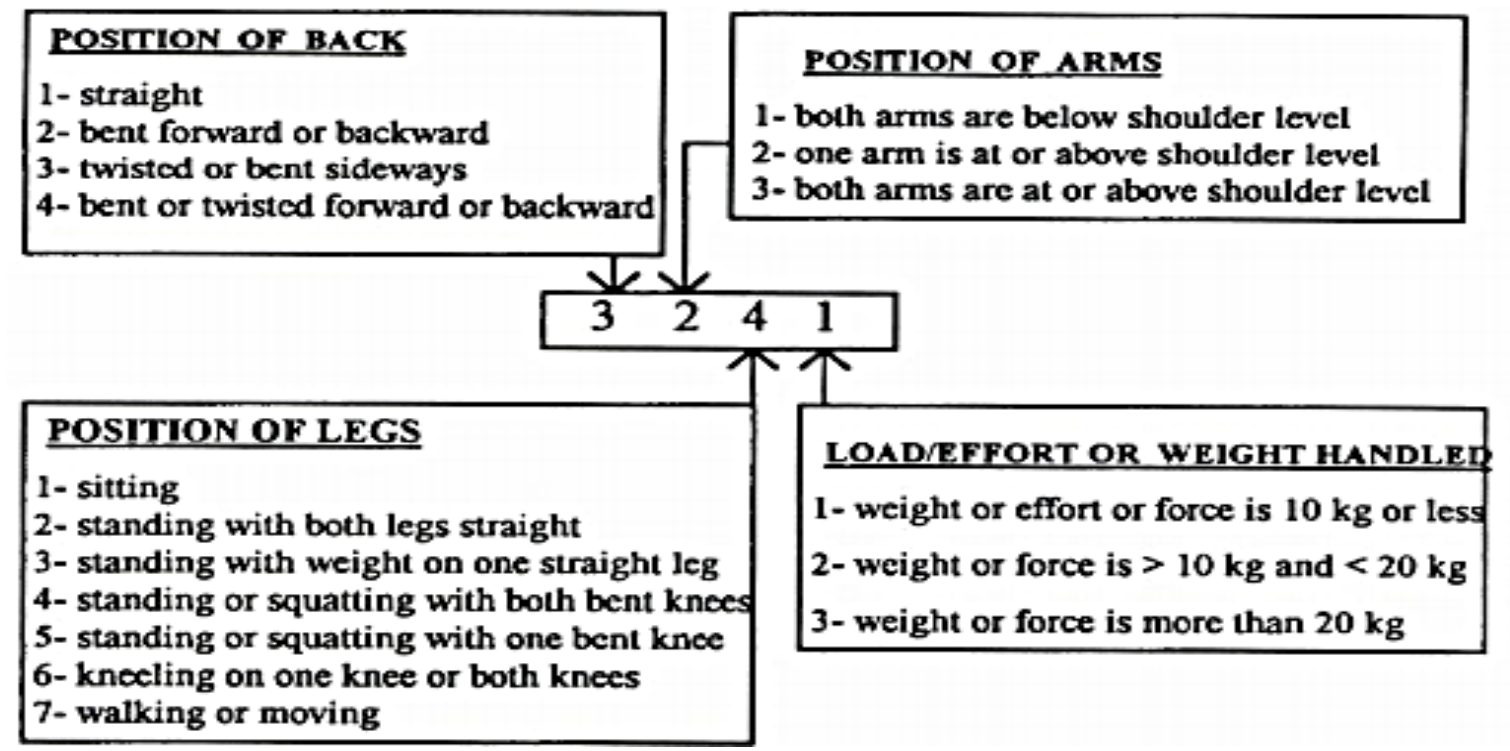

Gambar 2. Kode Identifikasi OWAS [8] 
Semakin tinggi tingkat IRHR semakin tinggi pula konsumsi energi dan rasa lelah pekerja. Pengukuran denyut jantung akan dilakukan menggunakan Heart Rate Monitor dan Smartwatch Garmin 910 XT. Berikut ini merupakan kategori pekerjaan berdasarkan indeks IRHR yang dapat dilihat pada Tabel 4.

\begin{tabular}{lc}
\multicolumn{2}{c}{ Tabel 4. Kategori Berdasarkan IRHR } \\
\hline \multicolumn{1}{c}{ Kategori } \\
Pekerjaan & Nilai IRHR \\
\hline Ringan & $1,00<$ IRHR $<1,25$ \\
Sedang & $1,25<$ IRHR $<1,5$ \\
Berat & $1,5<$ IRHR $<1,75$ \\
Sangat berat & $1,75<$ IRHR $<2,00$ \\
Luar biasa berat & $2,00<$ IRHR \\
\hline
\end{tabular}

\section{METODOLOGI PENELITIAN}

Penelitian akan dilakukan pada pekerja bagian stasiun kerja carding dan packing dacron PT. XYZ yang bertempatkan di Jalan Industri Raya, Sukadamai, Cikupa, Tangerang, Banten. Langkah-langkah penelitian mulai dari studi pustaka, hingga kesimpulan yang dilakukan dalam penulisan skripsi ini akan digambarkan dalam bentuk flowchart yang dapat dilihat pada Gambar 3.

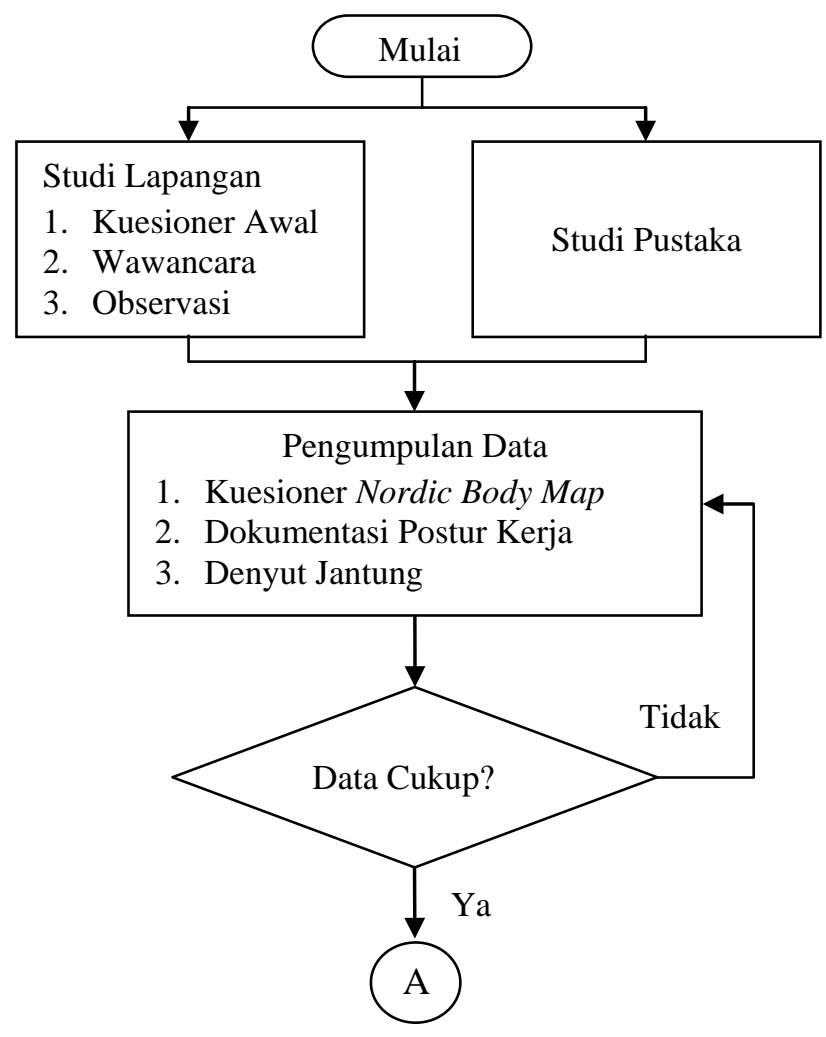

Gambar 3. Flowchart Penelitian
Lanjutan Gambar 3. Flowchart Penelitian

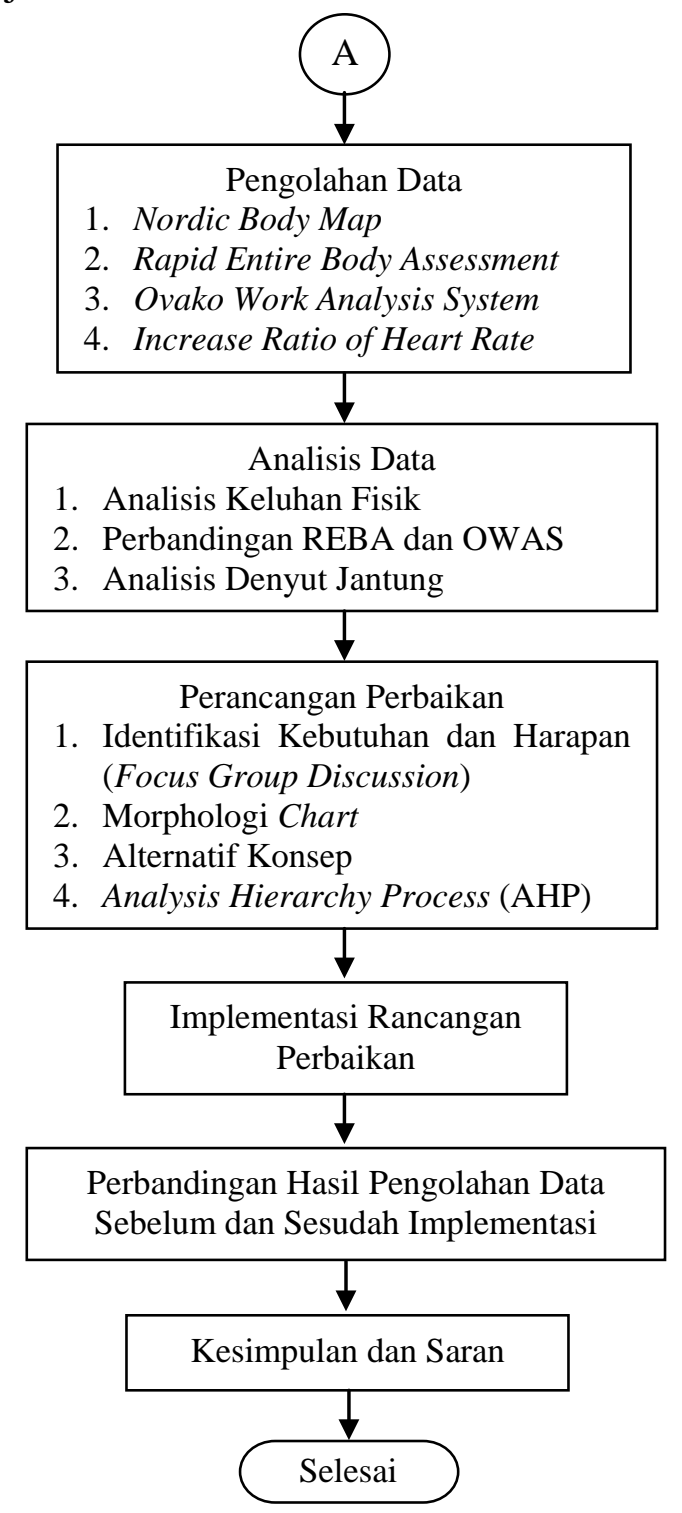

Setelah dilakukan analisis dan diketahui bagian yang memerlukan perbaikan segera, maka akan dilakukan perancangan perbaikan dengan identifikasi kebutuhan dan harapan pekerja melalui wawancara dan diskusi, pembuatan morphology chart, dan perancangan alternatif konsep. Pemilihan konsep akan dilakukan dengan Analytical Hierarchy Process (AHP) dan pembobotan rating. Data kuesioner AHP akan dibagikan terhadap responden berupa ahli akademisi dalam bidang ilmu ergonomi, manajer pabrik dan supervisor stasiun kerja.

\section{PERANCANGAN PERBAIKAN Morphology Chart}

Alat bantu yang akan dirancang terdapat dua jenis yaitu alat bantu carding dan alat bantu 
Perbaikan Stasiun Kerja Packing dan Carding Fiber Dacron (Polietilena Tereftalat) untuk Mencegah Musculoskeletal Disorder (MSDs) pada Pekerja PT. XYZ Cikupa Tangerang

Lamto Widodo, Adianto dan Felicia

packing. Alat bantu carding yang akan dirancang berupa sekop untuk mengambil dacron dari lantai sedangkan alat bantu packing yang akan dirancang berupa meja packing yang dapat menampung dacron. Masing-masing morphology chart untuk alat bantu carding dan alat bantu packing dapat dilihat pada Tabel 5 dan Tabel 6.

\section{Alternatif Rancangan}

Berdasarkan morphology chart yang telah dibuat, maka dapat dibuat alternatif rancangan yang dapat dilihat pada Tabel 7 dan Tabel 8 .

Tabel 5. Morphology Chart Alat Bantu Carding

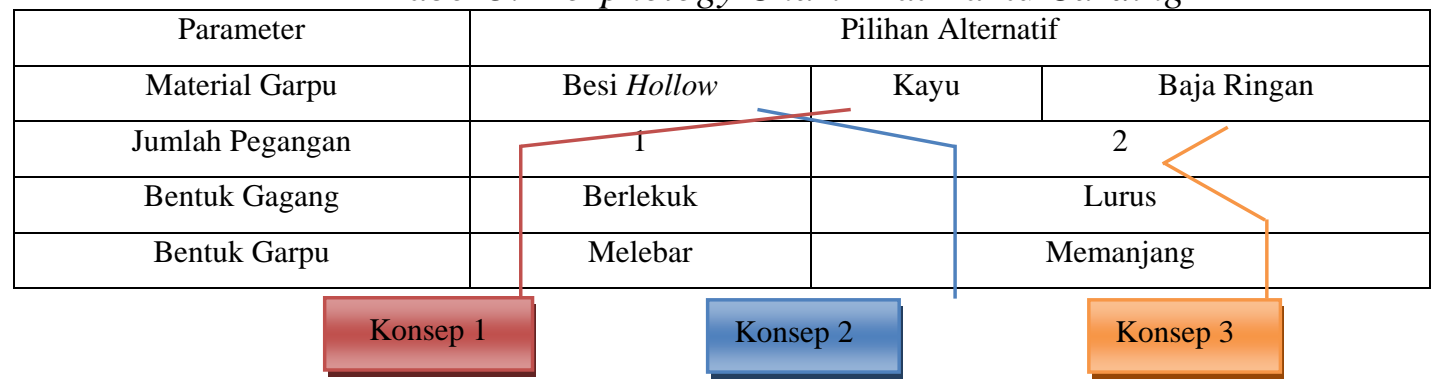

Tabel 6. Morphology Chart Alat Bantu Packing

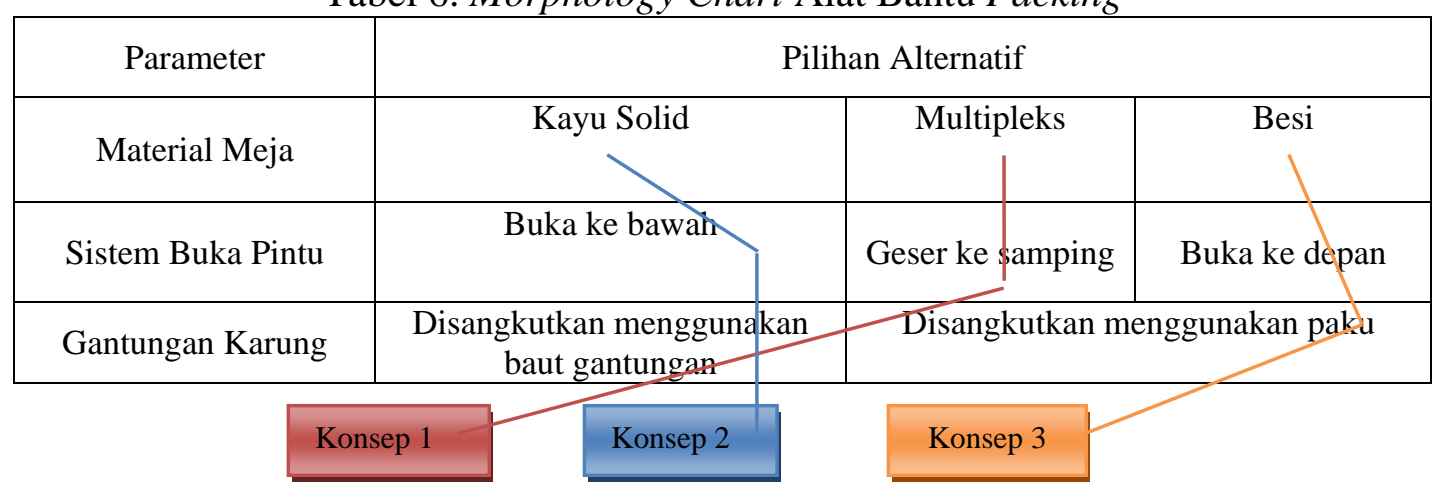

Tabel 7. Alternatif Rancangan Alat Bantu Carding

\begin{tabular}{|c|c|c|}
\hline Konsep & Gambar Alternatif & Deskripsi \\
\hline 1 & 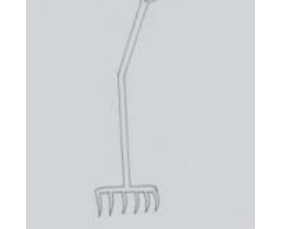 & $\begin{array}{l}\text { Material Kayu } \\
\text { Jumlah pegangan } 1 \\
\text { Bentuk gagang berlekuk } \\
\text { Bentuk garpu melebar }\end{array}$ \\
\hline 2 & סחד & $\begin{array}{l}\text { Material besi ringan } \\
\text { Jumlah pegangan 2 } \\
\text { Bentuk gagang lurus } \\
\text { Bentuk garpu memanjang }\end{array}$ \\
\hline 3 & 유 & $\begin{array}{l}\text { Material Aluminium } \\
\text { Jumlah pegangan 2 } \\
\text { Bentuk gagang lurus } \\
\text { Bentuk garpu memanjang }\end{array}$ \\
\hline
\end{tabular}


Tabel 8. Alternatif Rancangan Meja Packing

\begin{tabular}{lll}
\hline Konsep & Deskripsi \\
\hline 2 & $\begin{array}{l}\text { Material kayu solid } \\
\text { Sistem pintu buka ke bawah } \\
\text { Karung disangkutkan pada paku }\end{array}$ \\
\hline & $\begin{array}{l}\text { Material multipleks } \\
\text { Sistem pintu geser ke samping } \\
\text { Karung digantungkan pada } \\
\text { penjepit }\end{array}$ \\
\hline
\end{tabular}

Tabel 9. Pemilihan Alternatif Alat Bantu Carding

\begin{tabular}{|c|c|c|c|c|c|c|c|}
\hline \multirow{3}{*}{ Kriteria Seleksi } & \multirow{3}{*}{ Beban } & \multicolumn{6}{|c|}{ Alat Bantu Carding } \\
\hline & & \multicolumn{2}{|c|}{ Alternatif 1} & \multicolumn{2}{|c|}{ Alternatif 2} & \multicolumn{2}{|c|}{ Alternatif 3} \\
\hline & & Rating & $\begin{array}{c}\text { Nilai } \\
\text { Beban }\end{array}$ & Rating & $\begin{array}{c}\text { Nilai } \\
\text { Beban }\end{array}$ & Rating & $\begin{array}{l}\text { Nilai } \\
\text { Beban }\end{array}$ \\
\hline Keringanan bahan & 0,4508 & 1 & 0,4508 & 4 & 1,8032 & 3 & 1,3524 \\
\hline Keunikan desain & 0,1052 & 4 & 0,4209 & 3 & 0,3157 & 4 & 0,4209 \\
\hline Kenyamanan pegangan & 0,2321 & 3 & 0,6964 & 3 & 0,6964 & 3 & 0,6964 \\
\hline Variasi ketinggian pegangan & 0,1185 & 1 & 0,1185 & 3 & 0,3554 & 3 & 0,3554 \\
\hline Banyak tampungan dacron & 0,0934 & 2 & 0,1867 & 2 & 0,1867 & 2 & 0,1867 \\
\hline Total nilai & & \multicolumn{2}{|c|}{1,8733} & \multicolumn{2}{|c|}{3,3574} & \multicolumn{2}{|c|}{3,0119} \\
\hline Peringkat & & \multicolumn{2}{|c|}{3} & \multicolumn{2}{|c|}{1} & \multicolumn{2}{|c|}{2} \\
\hline Lanjutkan? & & \multicolumn{2}{|c|}{ Tidak } & \multicolumn{2}{|c|}{$\mathrm{Ya}$} & \multicolumn{2}{|c|}{ Tidak } \\
\hline
\end{tabular}

\section{Pemilihan Alternatif}

Setelah didesain hasil rancangan, maka perlu dilakukan pemilihan alternatif dengan menggunakan perhitungan bobot dan rating. Bobot didapatkan melalui kuesioner AHP kepada tiga orang ahli yaitu ahli akademisi bidang ilmu ergonomi, ahli manajer pabrik dan ahli supervisor stasiun kerja yang perhitungannya akan disertakan dalam lampiran. Rating memiliki skala 1 sampai 5 di mana semakin tinggi rating yang diberikan maka semakin sesuai alternatif rancangan dengan referensi kriteria. Pemilihan alternatif alat bantu carding dan packing dapat dilihat pada Tabel 9 dan Tabel 10.

Berdasarkan pemilihan alternatif, maka terpilih alat bantu carding dan alat bantu packing yang dapat dilihat pada Gambar 4 dan Gambar 5. 
Tabel 10. Pemilihan Alternatif Alat Bantu Packing

\begin{tabular}{|c|c|c|c|c|c|c|c|}
\hline \multirow{3}{*}{ Kriteria Seleksi } & \multirow{3}{*}{ Beban } & \multicolumn{6}{|c|}{ Alat Bantu Packing } \\
\hline & & \multicolumn{2}{|c|}{ Alternatif 1} & \multicolumn{2}{|c|}{ Alternatif 2} & \multicolumn{2}{|c|}{ Alternatif 3} \\
\hline & & Rating & $\begin{array}{c}\text { Nilai } \\
\text { Beban }\end{array}$ & Rating & $\begin{array}{c}\text { Nilai } \\
\text { Beban }\end{array}$ & Rating & $\begin{array}{c}\text { Nilai } \\
\text { Beban }\end{array}$ \\
\hline Penggunaan mudah & 0,3710 & 2 & 0,7421 & 4 & 1,4842 & 3 & 1,1131 \\
\hline Desain sederhana & 0,1339 & 2 & 0,2679 & 3 & 0,4018 & 2 & 0,2679 \\
\hline Keamanan alat & 0,4950 & 3 & 1,4851 & 4 & 1,9801 & 3 & 1,4851 \\
\hline Total nilai & & \multicolumn{2}{|c|}{2} & \multicolumn{2}{|r|}{4} & \multicolumn{2}{|c|}{3} \\
\hline Peringkat & & \multicolumn{2}{|c|}{3} & \multicolumn{2}{|c|}{1} & \multicolumn{2}{|c|}{2} \\
\hline Lanjutkan? & & \multicolumn{2}{|c|}{ Tidak } & \multicolumn{2}{|c|}{$\mathrm{Ya}$} & \multicolumn{2}{|c|}{ Tidak } \\
\hline
\end{tabular}

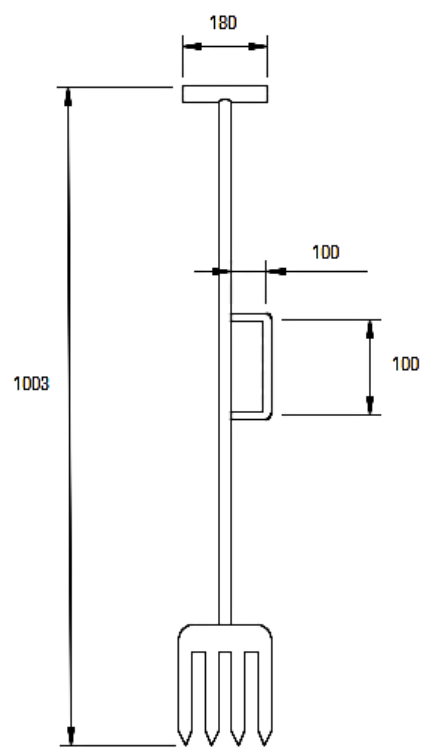

Gambar 4. Alat Bantu Carding
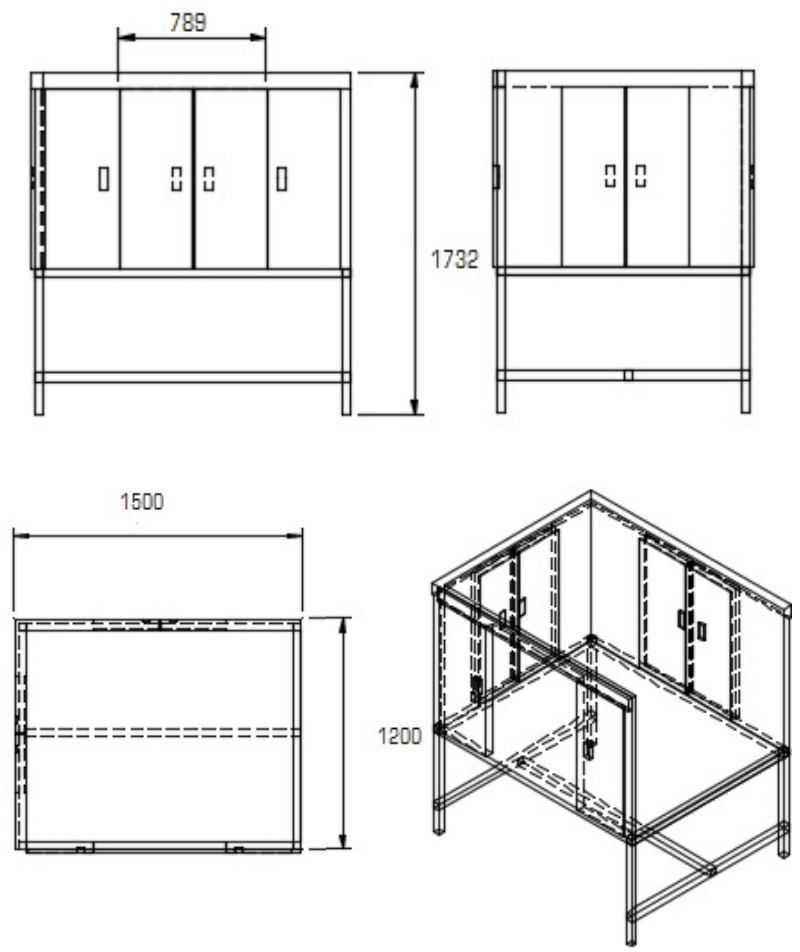

Gambar 5. Alat Bantu Packing

\section{HASIL DAN PEMBAHASAN}

Nordic Body Map

Berdasarkan kuesioner nordic body map yang dilampirkan, dapat disimpulkan urutan keluhan fisik total pekerja bagian carding dan packing dacron dari yang terbesar hingga terkecil dapat dilihat pada Tabel 11.

Tabel 11. Urutan Total Keluhan Fisik Sebelum Implementasi

\begin{tabular}{|c|c|c|c|c|}
\hline Bagian Tubuh & $\begin{array}{l}\text { Agak } \\
\text { Sakit }\end{array}$ & Sakit & $\begin{array}{c}\text { Sangat } \\
\text { Sakit }\end{array}$ & Total \\
\hline Punggung & 3 & 3 & - & 6 \\
\hline Bahu kiri & 1 & 3 & - & 4 \\
\hline Bahu kanan & 1 & 3 & - & 4 \\
\hline Pinggang & 3 & 1 & - & 4 \\
\hline Leher atas & 4 & - & - & 4 \\
\hline Bawah pinggang & 4 & - & - & 4 \\
\hline $\begin{array}{l}\text { Lengan bawah } \\
\text { kanan }\end{array}$ & 3 & 1 & - & 4 \\
\hline $\begin{array}{l}\text { Pergelangan } \\
\text { tangan kanan }\end{array}$ & 1 & 2 & - & 3 \\
\hline Leher bawah & 2 & 1 & - & 3 \\
\hline $\begin{array}{l}\text { Lengan atas } \\
\text { kanan }\end{array}$ & 2 & 1 & - & 3 \\
\hline Pantat & 2 & - & - & 2 \\
\hline Tangan kiri & 2 & - & - & 2 \\
\hline Tangan kanan & 2 & - & - & 2 \\
\hline Lutut kiri & 2 & - & - & 2 \\
\hline Lutut kanan & 2 & - & - & 2 \\
\hline $\begin{array}{l}\text { Pergelangan kaki } \\
\text { kanan }\end{array}$ & - & 1 & - & 1 \\
\hline Siku kiri & - & 1 & - & 1 \\
\hline Lengan atas kiri & 1 & - & - & 1 \\
\hline Siku kanan & 1 & - & - & 1 \\
\hline $\begin{array}{l}\text { Lengan bawah } \\
\text { kiri }\end{array}$ & 1 & - & - & 1 \\
\hline $\begin{array}{l}\text { Pergelangan } \\
\text { tangan kiri }\end{array}$ & 1 & - & - & 1 \\
\hline Paha kiri & 1 & - & - & 1 \\
\hline Betis kiri & 1 & - & - & 1 \\
\hline Betis kanan & 1 & - & - & 1 \\
\hline $\begin{array}{l}\text { Pergelangan kaki } \\
\text { kiri }\end{array}$ & 1 & - & - & 1 \\
\hline
\end{tabular}


Tabel 11. Urutan Total Keluhan Fisik Sebelum Implementasi

\begin{tabular}{lcccc}
\hline Bagian Tubuh & $\begin{array}{c}\text { Agak } \\
\text { Sakit }\end{array}$ & Sakit & $\begin{array}{c}\text { Sangat } \\
\text { Sakit }\end{array}$ & Total \\
\hline Paha kanan & - & - & - & - \\
$\begin{array}{l}\text { Telapak kaki kiri } \\
\begin{array}{l}\text { Telapak kaki } \\
\text { kanan }\end{array}\end{array}$ & - & - & - & - \\
\hline
\end{tabular}

Keluhan tertinggi berada di area punggung di mana keluhan tersebut umumnya disebabkan oleh gerakan membungkuk yang dilakukan secara terus-menerus.

Setelah dilakukan implementasi perbaikan, terdapat pengurangan keluhan fisik pada pekerja yang dapat dilihat pada Tabel 12.

Tabel 12. Urutan Total Keluhan Fisik Setelah Implementasi

\begin{tabular}{|c|c|c|c|c|c|}
\hline \multirow{2}{*}{ No } & \multirow{2}{*}{ Jenis Keluhan } & \multicolumn{4}{|c|}{ Tingkat Keluhan } \\
\hline & & A & B & $\mathrm{C}$ & $\mathrm{D}$ \\
\hline 0 & Sakit leher atas & 10 & 2 & & \\
\hline 1 & Sakit leher bawah & 12 & & & \\
\hline 2 & Sakit bahu kiri & 10 & 2 & & \\
\hline 3 & Sakit bahu kanan & 10 & 2 & & \\
\hline 4 & Sakit lengan atas kiri & 12 & & & \\
\hline 5 & Sakit punggung & 11 & 1 & & \\
\hline 6 & Sakit lengan atas kanan & 11 & 1 & & \\
\hline 7 & Sakit pinggang & 11 & 1 & & \\
\hline 8 & Sakit bawah pinggang & 11 & 1 & & \\
\hline 9 & Sakit pantat & 12 & & & \\
\hline 10 & Sakit siku kiri & 10 & 1 & 1 & \\
\hline 11 & Sakit siku kanan & 12 & & & \\
\hline 12 & Sakit lengan bawah kiri & 11 & 1 & & \\
\hline 13 & $\begin{array}{l}\text { Sakit lengan bawah } \\
\text { kanan }\end{array}$ & 11 & & 1 & \\
\hline 14 & $\begin{array}{l}\text { Sakit pergelangan } \\
\text { tangan kiri }\end{array}$ & 10 & 2 & & \\
\hline 15 & $\begin{array}{l}\text { Sakit pergelangan } \\
\text { tangan kanan }\end{array}$ & 10 & 2 & & \\
\hline 16 & Sakit tangan kiri & 10 & 2 & & \\
\hline 17 & Sakit tangan kanan & 11 & 1 & & \\
\hline 18 & Sakit paha kiri & 12 & & & \\
\hline 19 & Sakit paha kanan & 11 & 1 & & \\
\hline 20 & Sakit lutut kiri & 11 & 1 & & \\
\hline 21 & Sakit lutut kanan & 12 & & & \\
\hline 22 & Sakit betis kiri & 12 & & & \\
\hline 23 & Sakit betis kanan & 11 & 1 & & \\
\hline 24 & $\begin{array}{l}\text { Sakit pergelangan } \\
\text { kaki kiri }\end{array}$ & 12 & & & \\
\hline 25 & $\begin{array}{l}\text { Sakit pergelangan } \\
\text { kaki kanan }\end{array}$ & 12 & & & \\
\hline 26 & $\begin{array}{l}\text { Sakit telapak kaki } \\
\text { kiri }\end{array}$ & 10 & 2 & & \\
\hline 27 & $\begin{array}{l}\text { Sakit telapak kaki } \\
\text { kanan }\end{array}$ & 12 & & & \\
\hline
\end{tabular}

Terjadi pengurangan pada bagian punggung yang awalnya sebanyak 6 keluhan menjadi 1 keluhan, bahu kiri, bahu kanan, leher, pinggang dan sebagainya.

\section{REBA}

Untuk melakukan analisis REBA, maka akan dipilih postur-postur ekstrem pada proses carding dan packing dacron. Pemberian sudut dilakukan dengan bantuan program Corel Draw X8. Analisis REBA dilakukan dengan bantuan REBA Worksheet yang dilampirkan. Untuk penelitian ini, analisis REBA diambil dari 7 postur ekstrem proses kerja carding dan packing yang masing-masing mewaklili gerakan kerja proses carding dan packing yang hasilnya dapat dilihat pada Tabel 13.

Tabel 13. Analisis REBA Sebelum Implementasi

\begin{tabular}{|c|c|c|}
\hline Postur & $\begin{array}{c}\text { Skor } \\
\text { REBA }\end{array}$ & $\begin{array}{c}\text { Analisis Tingkat Resiko } \\
\text { REBA }\end{array}$ \\
\hline 1 & 11 & $\begin{array}{l}\text { Sangat tinggi, perbaikan \& } \\
\text { pengukuran lebih lanjut } \\
\text { dibutuhkan segera }\end{array}$ \\
\hline 2 & 12 & $\begin{array}{l}\text { Sangat tinggi, perbaikan \& } \\
\text { pengukuran lebih lanjut } \\
\text { dibutuhkan segera }\end{array}$ \\
\hline 3 & 11 & $\begin{array}{l}\text { Sangat tinggi, perbaikan \& } \\
\text { pengukuran lebih lanjut } \\
\text { dibutuhkan segera }\end{array}$ \\
\hline 4 & 9 & $\begin{array}{l}\text { Tinggi, perbaikan \& } \\
\text { pengukuran lebih lanjut } \\
\text { dibutkan ke depannya }\end{array}$ \\
\hline 5 & 11 & $\begin{array}{l}\text { Sangat tinggi, perbaikan \& } \\
\text { pengukuran lebih lanjut } \\
\text { dibutuhkan segera }\end{array}$ \\
\hline 6 & 9 & $\begin{array}{l}\text { Tinggi, perbaikan \& } \\
\text { pengukuran lebih lanjut } \\
\text { dibutkan ke depannya }\end{array}$ \\
\hline 7 & 10 & $\begin{array}{l}\text { Tinggi, perbaikan \& } \\
\text { pengukuran lebih lanjut } \\
\text { dibutkan ke depannya }\end{array}$ \\
\hline
\end{tabular}

Berdasarkan hasil analisis REBA, diketahui bahwa postur 1, 2, 3, dan 5 memiliki level resiko sangat tinggi dan memerlukan perbaikan segera/secepatnya.

Setelah dilakukan implementasi perbaikan, terdapat pengurangan skor REBA untuk proses carding dan packing yang dapat dilihat pada Tabel 14. 
Tabel 14. Analisis REBA Setelah Implementasi

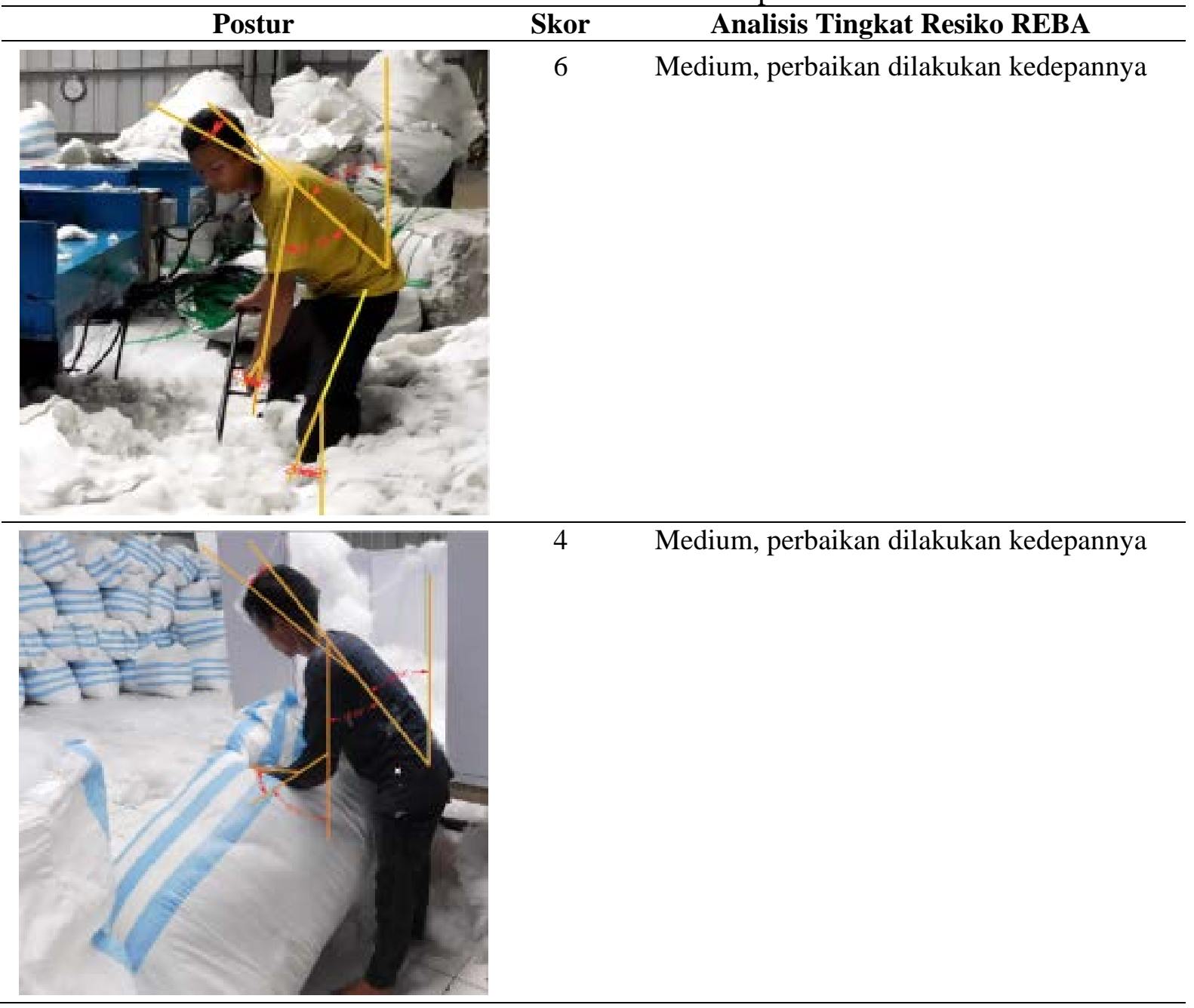

Tabel 15. Hasil Analisis OWAS

\begin{tabular}{ccl}
\hline Postur & Kode & \multicolumn{1}{c}{ Penilaian Analisis } \\
\hline 1 & 2331 & Kategori 3, jelas berbahaya perlu dilakukan perbaikan segera/secepatnya \\
2 & 2331 & Kategori 3, jelas berbahaya perlu dilakukan perbaikan segera/secepatnya \\
3 & 2131 & Kategori 2, sedikit berbahaya perlu dilakukan perbaikan kedepannya \\
4 & 2141 & Kategori 3, jelas berbahaya perlu dilakukan perbaikan segera/secepatnya \\
5 & 2331 & Kategori 3, jelas berbahaya perlu dilakukan perbaikan segera/secepatnya \\
6 & 2121 & Kategori 2, sedikit berbahaya perlu dilakukan perbaikan kedepannya \\
7 & 2321 & Kategori 2, sedikit berbahaya perlu dilakukan perbaikan kedepannya \\
\hline
\end{tabular}

\section{OWAS}

Analisis OWAS dilakukan untuk memperhitungkan postur tubuh dan disesuaikan dengan standar kategori yang telah ditentukan. Analisis OWAS akan dilakukan menggunakan postur yang sama sebagai perbandingan dengan analisis REBA. Untuk hasil analisis OWAS dari 7 postur tersebut dapat dilihat pada Tabel 15.

Setelah dilakukan penyesuaian terhadap tabel OWAS, berdasarkan hasil analisis OWAS, postur 1, 2, 4, dan 5 masuk ke dalam kategori 3 dimana berarti postur tersebut memerlukan perbaikan segera/ secepatnya.

Setelah implementasi, terdapat perubahan kategori OWAS yang dapat dilihat pada Tabel 16.

\section{IRHR}

Analisis IRHR dilakukan berdasarkan denyut jantung istirahat dan denyut jantung kerja dari pekerja yang masing-masing dapat dilihat pada Tabel 17 dan Tabel 18. 
Tabel 16. Hasil Analisis OWAS Setelah Implementasi

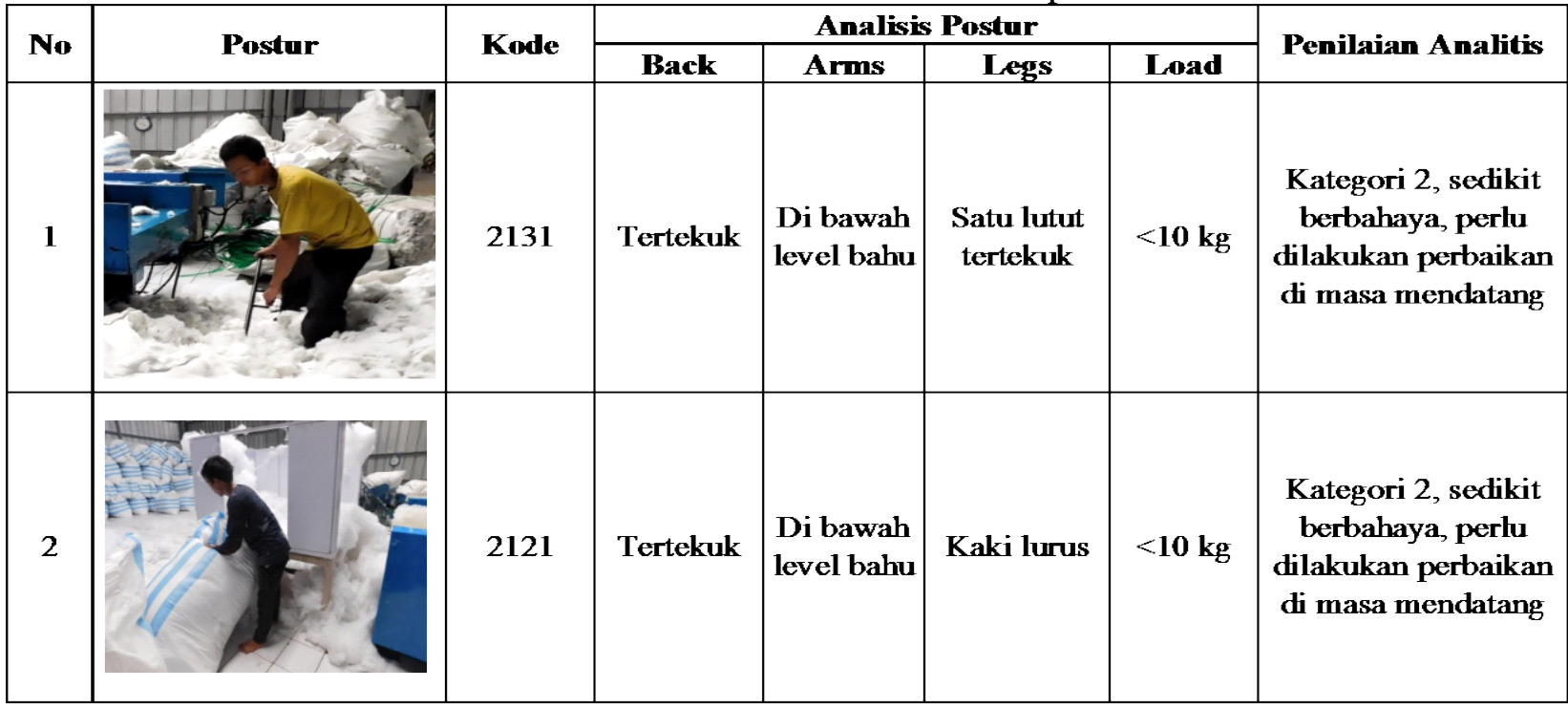

Tabel 17. Denyut Jantung Istirahat

Pekerja

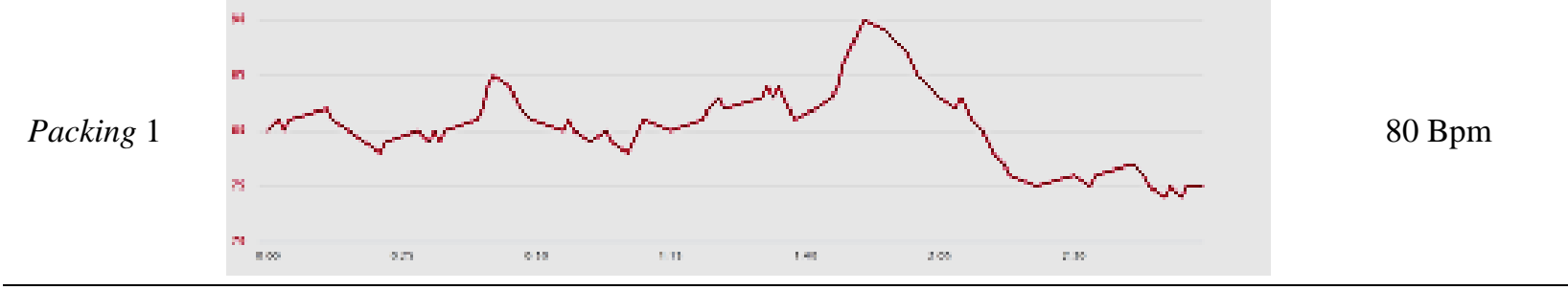

Packing 2

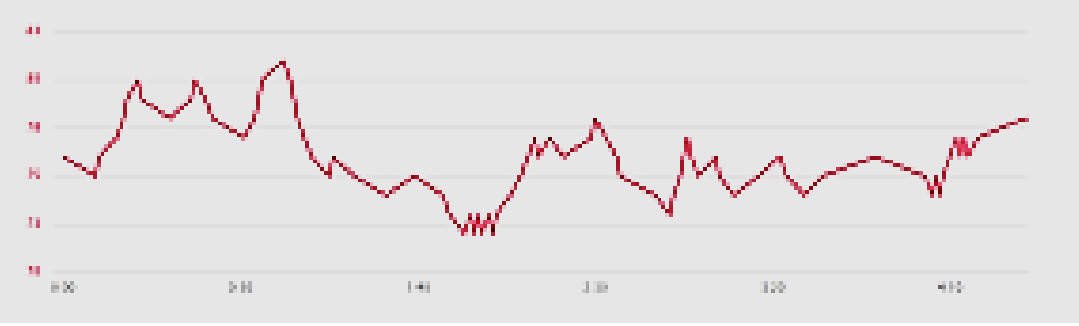

76 Bpm

Analisis IRHR dilakukan terhadap 1 pekerja carding dan 2 pekerja packing sehingga dihasilkan angka IRHR yang dapat dilihat pada Tabel 19.

Berdasarkan hasil analisis IRHR, didapatkan hasil pekerjaan carding dan packing dikategorikan sebagai pekerjaan berat.

Setelah dilakukan implementasi kembali dilakukan perhitungan denyut jantung pekerja sehingga didapatkan hasil adanya penurungan nilai IRHR yang dapat dilihat pada Tabel 20 hingga Tabel 22.

Tabel 19. Hasil IRHR Sebelum Implementasi

\begin{tabular}{ccc}
\hline Pekerja & IRHR & Kategori \\
\hline Carding & 1,5 & Berat \\
Packing 1 & 1,625 & Berat \\
Packing 2 & 1,618 & Berat \\
\hline
\end{tabular}


Tabel 18. Denyut Jantung Kerja

Pekerja

Tabel 20. Denyut Jantung Sebelum Bekerja

\begin{tabular}{c|c|c}
\hline Pekerja & Gambar & Denyut Jantung \\
\hline Carding & & $79 \mathrm{Bpm}$ \\
\hline Packing 1 & & $76 \mathrm{Bpm}$ \\
\hline Packing 2 & & $75 \mathrm{Bpm}$ \\
\hline
\end{tabular}

Tabel 21. Denyut Jantung Saat Bekerja

\begin{tabular}{c|c|c}
\hline Pekerja & \multicolumn{1}{|c|}{ Gambar } & Denyut Jantung \\
\hline Carding & & $114 \mathrm{Bpm}$ \\
\hline Packing 1 & & $100 \mathrm{Bpm}$ \\
\hline Packing 2 & & $110 \mathrm{Bpm}$ \\
\hline
\end{tabular}

Tabel 22. Hasil IRHR Setelah Implementasi

\begin{tabular}{ccc}
\hline Pekerja & IRHR & Kategori \\
\hline Carding & 1.443 & Sedang \\
Packing 1 & 1.316 & Sedang \\
Packing 2 & 1.466 & Sedang \\
\hline
\end{tabular}

\section{KESIMPULAN}

Berdasarkan penelitian yang telah dilakukan, maka dapat ditarik beberapa kesimpulan yaitu:

Keluhan tertinggi dialami oleh pekerja pada bagian punggung yang disebabkan oleh gerakan membungkuk repetitif dengan sudut yang ekstrem. Kemudian diikuti dengan bahu, pinggang, leher atas, lengan, hingga pergelangan tangan. Tidak terdapat keluhan pada paha kanan dan telapak kaki.

Resiko tertinggi pada proses carding dan packing berada pada saat proses pengambilan dacron yang mengharuskan gerakan membungkuk dengan sudut ekstrem sebab dacron ditampung di lantai kerja. Dibuktikan dengan skor REBA yang mencapai 12 saat proses carding dan 11 saat proses packing.

Usulan perbaikan yang diberikan adalah dengan menggunakan garpu dacron untuk proses carding dan meja packing untuk proses packing sehhingga dapat mengurangi derajat membungkuknya pekerja dan mengurangi rasa lelah pekerja.

Setelah diimplementasikan terjadi pengurangan skor REBA saat proses carding menjadi 6 dan proses packing menjadi 4 . 
Kemudian kategori OWAS yang tadinya 3 menjadi 2. Serta analisis IRHR yang awalnya tergolong pekerjaan berat menjadi tergolong pekerjaan sedang. Terdapat pula penurunan keluhan fisik pekerja pada bagian tubuh tertentu seperti punggung, bahu, dan sebagainya.

\section{DAFTAR PUSTAKA}

[1] Sutalaksana, Iftikar Z., Ruhana Anggawisastra dan Jann $\mathrm{H}$. Tjakraatmadja. 2006. Teknik Perancangan Sistem Kerja. Bandung: Penerbit ITB.

[2] Panero, Julius dan Martin Zelnik. 2003. Human Dimension \& Interior Space. Trans. Djoeliana Kurniawan. Jakarta: Erlangga.

[3] Nurmianto, Eko. 1996. Ergonomi Konsep Dasar dan Aplikasinya. Jakarta: Guna Widya.

[4] Kourinka I \& al. Standardised Nordic Questionnaires for the Analysis of Musculoskeletal Symptoms. Applied Ergonomics 1987; 18(3):233-237.

[5] Hignett, Sue dan Lynn McAtamney. Rapid Entire Body Assessment (REBA). Applied Ergonomic 2000; 31:201-205.

[6] Stanton, Neville \& al. 2006. Handbook of Human Factors and Ergonomics Method. New York: CRC Press.

[7] Anggraini, Weisni dan Anda Mulya Pratama. Analisis Postur Kerja dengan
Menggunakan Metode Ovako Working Analysis System (OWAS) Pada Stasiun Pengepakan Bandela Karet (Studi Kasus di PT Riau Crumb Rubber Factory PekanBaru). Jurnal Sains, Teknologi dan Industri 2012; 10(1):10-18.

[8] Ahasan, M Rabiul \& al. Physical Workload Analysis Among Small Industry Activities Using Postural Data. International Journal of Occuptional Safety and Ergonomics 1996; 2(1):27-34.

[9] Karhu O \& al. Observing Working Posture in Industry: Example of OWAS Application. Applied Ergonomics 1981; 12(1):13-7.

[10] Syuaib, MF. 2003. Ergonomic Study on the Process of Mastering Tractor Operation. Desertasi. Tokyo University of Agriculture and Technology, Tokyo, Japan. 